\title{
Exposure to binge food in bulimia nervosa: finger pulse amplitude as a potential masure of urge to eat and predictor of food intake
}

Citation for published version (APA):

Nederkoorn, C., Smulders, F., Havermans, R., \& Jansen, A. (2004). Exposure to binge food in bulimia nervosa: finger pulse amplitude as a potential masure of urge to eat and predictor of food intake. Appetite, 42(2), 125-130. https://doi.org/10.1016/j.appet.2003.11.001

Document status and date:

Published: 01/04/2004

DOI:

10.1016/j.appet.2003.11.001

Document Version:

Publisher's PDF, also known as Version of record

Document license:

Taverne

Please check the document version of this publication:

- A submitted manuscript is the version of the article upon submission and before peer-review. There can be important differences between the submitted version and the official published version of record.

People interested in the research are advised to contact the author for the final version of the publication, or visit the DOI to the publisher's website.

- The final author version and the galley proof are versions of the publication after peer review.

- The final published version features the final layout of the paper including the volume, issue and page numbers.

Link to publication

\footnotetext{
General rights rights.

- You may freely distribute the URL identifying the publication in the public portal. please follow below link for the End User Agreement:

www.umlib.nl/taverne-license

Take down policy

If you believe that this document breaches copyright please contact us at:

repository@maastrichtuniversity.nl

providing details and we will investigate your claim.
}

Copyright and moral rights for the publications made accessible in the public portal are retained by the authors and/or other copyright owners and it is a condition of accessing publications that users recognise and abide by the legal requirements associated with these

- Users may download and print one copy of any publication from the public portal for the purpose of private study or research.

- You may not further distribute the material or use it for any profit-making activity or commercial gain

If the publication is distributed under the terms of Article $25 \mathrm{fa}$ of the Dutch Copyright Act, indicated by the "Taverne" license above, 


\title{
Exposure to binge food in bulimia nervosa: finger pulse amplitude as a potential measure of urge to eat and predictor of food intake
}

\author{
Chantal Nederkoorn*, Fren Smulders, Remco Havermans, Anita Jansen \\ Department of Experimental Psychology, Faculty of Psychology, Maastricht University, P.O. Box 616, 6200 MD Maastricht, The Netherlands
}

Received 1 May 2003; accepted 4 November 2003

\begin{abstract}
The conditioning model of binge eating states that cues such as the sight, smell and taste of binge food prepare the binger's body for the intake of large amounts of food. The bodily preparations are supposed to be felt as an almost irresistible urge to binge. In the present study, the validity of the model was tested. Clinical binge eaters (bulimia nervosa patients) and healthy control participants were exposed to their most favourite food and physiological responding was measured. As predicted, the exposure increased physiological responding and led to more intense urge to eat, but no significant differences between the bulimics and the normal controls were found. For both groups, increased urge to eat appeared to be related to finger pulse amplitude (FPA), and both the FPA and the self-reported urge to eat predicted increased caloric intake during a subsequent taste test. It is concluded that changes in FPA might reflect classically conditioned bodily responses that prepare for eating.
\end{abstract}

(C) 2003 Elsevier Ltd. All rights reserved.

Keywords: Bulimia nervosa; Binge eating; Cue exposure; Cue reactivity; Craving

\section{Introduction}

Binge eating is a particular form of overeating that not only characterizes bulimia nervosa but is also common in a substantial part of anorexia nervosa patients and the eating disorders not otherwise specified (i.e. the binge eating disorder and other atypical eating disorders; APA, 1994). It is defined as the intake of a definitely large amount of food in a short period of time during which loss of control is experienced (APA, 1994). Although the prevalence of binge eating across the weight and eating disorder spectrum is ample, almost nothing is known about its maintaining mechanisms. There is some evidence that classically conditioned mechanisms might play a role in binge eating (Jansen, 1998). The conditioning model of binge eating states that when cues such as the sight, smell and taste of binge food are systematically paired with actual binge eating, an association between the cues at the one hand and the intake of binge food at the other hand is easily learned. Learning principles say that the learning of such an association will be stronger when the cues are more reliable

\footnotetext{
* Corresponding author.

E-mail address: c.nederkoorn@psychology.unimaas.nl (C.Nederkoorn).
}

predictors of intake, and when the amount of food eaten is larger (in terms of consumed kilocalories) (Jansen, 1998). The conditioning model of binge eating declares that during confrontation with predicting cues, such as the sight, smell and taste of binge food, the binger's body will expect a binge and is going to prepare for the excessive intake. The binger's body will anticipate and prepare physiologically for the processing of a large amount of food. The conditioning model further predicts that these preparatory responses are subjectively experienced as an almost irresistible urge to binge or craving (Jansen, 1998).

Research into the validity of the conditioning model of binge eating is, however, scarcely out of the egg. There is empirical support for the hypothesis that the self-reported craving during exposure to food cues differentiates eating disorder patients from normal controls (Bulik, Lawson, \& Carter, 1996; Karhunen, Lappalainen, Tammela, Turpeinen, \& Uusitupa, 1997; Staiger, Daw, \& McCarthy, 2000). It is well documented that exposure to food or food cues evokes physiological preabsorptive or cephalic phase responses in normal subjects, which gear the body up and serve to better use of nutrients (Mattes, 1997; Nederkoorn, Smulders, \& Jansen, 2000) and some studies show increased preabsorptive responding in binge eaters (Carter, Bulik, 
McIntosh, \& Joyce, 2001; Karhunen, Lappalainen, Vanninen, Kuikka, \& Uusitupa, 1997; Teff \& Engelman, 1996; Tepper, 1992; Tuomisto et al., 1999; Vögele, \& Florin, 1997). It has not yet been demonstrated convincingly that increased physiological responding during exposure is positively related to both an increased self-reported urge to eat and increased food intake after the exposure, a prediction that is made by the conditioning model. Vögele and Florin (1997) demonstrated a relation between physiological responding (sc. heart rate, HR) and desire to binge on one hand and an indirect measure of food intake on the other hand. In the present study, it was hypothesized that during food cue exposure, participants diagnosed with bulimia nervosa show increased physiological reactivity to the food cues and report a stronger urge to eat than normal controls. A second hypothesis is that, because of the increased cue reactivity, the bulimics eat more during a taste test following the cue exposure than the controls. Finally, it was predicted that food intake is positively related to the urge to eat and physiological responding.

\section{Method}

\section{Participants}

Fifty-one female eating disorder patients that announced for treatment in the Academic Unit for Cognitive Behaviour Therapy of the Community Mental Health Centre of Maastricht participated in the study. All patients were screened with the Dutch version of the Structured Clinical Interview for DSM IV Axis I (SCID-I; Spitzer \& Williams, 1986) and fulfilled the diagnostic criteria for bulimia nervosa. The patients were asked to participate in an experiment on the influence of binge food on the body and when they gave their written informed consent, favourite binge items were identified. The experiment took place before the treatment started. Twenty non-dieting female students without any eating disorder participated in the control group. There were no significant differences $(t<1)$ in Body Mass Index (BMI, the ratio of weight to squared height $\left.\left(\mathrm{kg} / \mathrm{m}^{2}\right)\right)$ between the patient group $(M=22.6$, $\mathrm{SD}=2.3)$ and the normal eating controls $(M=22.8$, $\mathrm{SD}=1.5)$.

\section{Assessment}

Subjective cue reactivity. Visual analogue scales (VASs) were used to measure state urge to eat, mood, and tension, ranging from 0 (no urge to eat at all, not at all depressed, not at all nervous) to 100 (intense urge to eat, very depressed, very nervous).

Physiological cue reactivity. HR, Finger Pulse Amplitude (FPA) and Skin Conductance Level (SCL) were measured as an index of physiological cue reactivity. It is expected that HR and skin conductance increase during food exposure, whereas FPA is expected to decrease, as more blood is flowing to the intestines for digestion of the expected food. Physiological measures were sampled at $1000 \mathrm{~Hz}$. and measures were made during the baseline (1 min), exposure period (10 $\mathrm{min})$ and taste period (10 $\mathrm{min})$. Three $\mathrm{Ag}-\mathrm{AgCl}$ were used to measure HR; two in the heart region and a reference electrode on the back. HR-waves were detected off-line with a template matching procedure, and beats per minute (bpm) were calculated. FPA was measured in arbitrary units (au) by a photoplethysmograph, placed by a clip on the middle finger of the non-dominant hand. SCL was measured in micro-Siemens $(\mu S)$ with three $\mathrm{Ag}-\mathrm{AgCl}$ electrodes, placed on the middle and ring finger of the non-dominant hand with the reference electrode on the back of the same hand.

Food intake. During the cue exposure and taste test, each patient was presented with large amounts of their most favourite and most frequently eaten binge food (their personal 'top four' of binge food). For each control participant, an idiosyncratic top four of most favourite and frequently eaten snacks were presented in large amounts. Every plate with food was weighed before the cue exposure and reweighed after the taste test. The amount of kilocalories per gram was determined for each food item and the total amount of calories eaten during the taste test was calculated.

\section{Procedure}

All participants were instructed to eat a meal of $100 \mathrm{kcal}$ $2 \mathrm{~h}$ before the experiment and to refrain from further eating, in order to standardize pre-experimental food intake. According to a self-report measure, they all followed these instructions. Each participant was run individually. After entering the laboratory, the participant received information regarding the experimental procedure, completed the VASs, and electrodes were attached. The participant was told that physiological reactivity to food would be measured. A round bench in front of the participant was tailored to her height so that it was just under her nose. After calibration and checking the physiological signals, she was instructed to sit quietly and relaxed. The bench was turning slowly, and every quarter of the plateau paused for a few seconds directly under the nose of the participant. Baseline measurements started (1 min), whereupon four plates filled with large amounts of the binge food (patients) or snacks (controls) were placed on the turning table, right under the nose of the participant. Then cue exposure started and the participant was instructed to smell the food intensely. After $10 \mathrm{~min}$ of exposure to the sight and smell of the food, the VASs were completed again. Next the participant was instructed to consume a small preload $(5 \mathrm{~g})$ of the binge or snack food, and she was invited to further taste the food and to eat as much of it as needed or wanted to complete a taste-questionnaire (containing items on the taste, e.g. sweetness of the foods, whether the subject likes the foods, and so on). The experimenter informed 
the participant that she was allowed to visit the toilet afterwards (giving the possibility to vomit, brush her teeth and take some sugarless chewing gum) and left the laboratory. Physiological measurements continued during the taste test. After $10 \mathrm{~min}$, the experimenter returned, detached the electrodes and debriefed the participant. Finally, her weight and height were measured and she was paid a small fee for participation.

\section{Analyses}

The data were analysed with ANOVA for repeated measures. Separate ANOVA's are presented for the effects of the exposure and the effects of the taste test. Due to apparatus failure or artefacts, the physiological data was not complete. Number of participants for each measure is reported in Tables 1 and 2 . Three bulimic subjects performed the taste tests for $5 \mathrm{~min}$ instead of $10 \mathrm{~min}$; of these subjects, the mean scores on physiological data over these $5 \mathrm{~min}$ are included in the analyses.

Because it is uncertain at which moment the effects of the exposure is at its top, and this timing can vary across subjects and physiological parameters, for each subject and parameter, the mean largest response over a $1 \mathrm{~min}$ period within $10 \mathrm{~min}$ exposure time is selected. The same analyses are done using the mean responses over the 10 min exposure

Table 1

Mean psychophysiological and subjective reactivity and standard deviation (SD) in patients diagnosed with bulimia nervosa and normal controls during baseline and cue exposure

\begin{tabular}{|c|c|c|c|c|c|c|}
\hline & \multicolumn{3}{|c|}{ Bulimia nervosa } & \multicolumn{3}{|c|}{ Normal controls } \\
\hline & $N$ & Mean & $\mathrm{SD}$ & $N$ & Mean & $\mathrm{SD}$ \\
\hline \multicolumn{7}{|c|}{ Heart rate (bpm) } \\
\hline Baseline & 51 & 73.6 & 10.4 & 20 & 74.1 & 9.6 \\
\hline Exposure & & 76.7 & 11.8 & & 77.7 & 8.7 \\
\hline \multicolumn{7}{|c|}{ Finger pulse amplitude (a.u.) } \\
\hline Baseline & 46 & 5.6 & 2.1 & 19 & 6.5 & 3.7 \\
\hline Exposure & & 7.5 & 3.0 & & 8.0 & 4.1 \\
\hline \multicolumn{7}{|c|}{ Skin conductance $(\mu S)$} \\
\hline Baseline & 46 & 3.6 & 1.7 & 14 & 4.1 & 1.5 \\
\hline Exposure & & 4.4 & 2.2 & & 4.8 & 1.6 \\
\hline \multicolumn{7}{|c|}{ Craving (VAS) } \\
\hline Baseline & 51 & 18.5 & 21.5 & 20 & 30.7 & 21.0 \\
\hline Exposure & & 55.9 & 30.5 & & 66.7 & 20.2 \\
\hline \multicolumn{7}{|c|}{ Depression (VAS) } \\
\hline Baseline & 51 & 29.1 & 27.4 & 20 & 12.3 & 15.6 \\
\hline Exposure & & 44.3 & 31.0 & & 16.9 & 20.7 \\
\hline \multicolumn{7}{|c|}{ Tension (VAS) } \\
\hline Baseline & 51 & 31.4 & 26.7 & 20 & 22.4 & 19.1 \\
\hline Exposure & & 49.9 & 30.8 & & 41.1 & 23.4 \\
\hline
\end{tabular}

Due to apparatus failure or artefacts, finger pulse and skin conductance, data for some subjects are missing.
Table 2

Food intake during the taste test and mean psychophysiological cue reactivity and standard deviation (SD) in patients diagnosed with bulimia nervosa and control participants during both the exposure and taste test

\begin{tabular}{|c|c|c|c|c|c|c|}
\hline & \multicolumn{3}{|c|}{ Bulimia nervosa } & \multicolumn{3}{|c|}{ Normal controls } \\
\hline & $N$ & Mean & SD & $N$ & Mean & SD \\
\hline Food intake (kcal) & 51 & 315 & 289 & 20 & 316 & 274 \\
\hline \multicolumn{7}{|l|}{ Heart rate $(\mathrm{bpm})$} \\
\hline Exposure & 44 & 76.4 & 12.1 & 20 & 77.7 & 8.7 \\
\hline Taste test & & 80.6 & 11.5 & & 81.6 & 10.1 \\
\hline \multicolumn{7}{|c|}{ Finger pulse amplitude (a.u.) } \\
\hline Exposure & 41 & 7.5 & 3.1 & 18 & 7.5 & 3.6 \\
\hline Taste test & & 6.5 & 3.0 & & 6.4 & 3.2 \\
\hline \multicolumn{7}{|c|}{ Skin conductance $(\mu S)$} \\
\hline Exposure & 42 & 4.5 & 2.2 & 14 & 4.8 & 1.6 \\
\hline Taste test & & 3.8 & 2.0 & & 4.4 & 1.5 \\
\hline
\end{tabular}

Due to apparatus failure or artefacts, data from some subjects are missing.

time, and over the first and the last $5 \mathrm{~min}$ exposure. The results from these analyses are not substantial different.

For the effect of the taste test on the physiological parameters, the mean largest response over 5 min was selected.

\section{Results}

Food cue exposure. The data are presented in Table 1. Hypothesis 1: During food cue exposure participants diagnosed with bulimia nerrosa show increased physiological reactivity to the food cues and report stronger urge to eat compared to normal controls. The 2 (Group: bulimics vs normal controls) $\times 2$ (Time: baseline vs exposure) ANOVA showed main effects of Time for HR, $F(1,69)=31.2, p<$ 0.001, FPA, $F(1,64)=28.3, p<0.001$, and SCL, $F(1,58)=24.6, p<0.001$, meaning that the exposure led to significantly increased physiological responses. No main effects for Group and no interaction effects were found (all $F^{\prime}$ s $<1$ ), meaning that there were no group differences in physiological responding between bulimics and normal controls.

The ANOVA further showed main effects of Time for craving, $F(1,69)=105, p<0.001$, depression, $F(1,69)=$ 9.9, $p<0.01$, and tension, $F(1,69)=52.3, p<0.001$, meaning that the exposure increased craving, depression and tension. Significant main effects of Group for craving, $F(1,69)=4.3, p<0.05$, and depression, $F(1,69)=12.4$, $p<0.01$, were also found. Table 1 shows that the bulimics reported less craving and more depression than the control participants during both the baseline and the exposure. No main Group effect for Tension was found, $F(1,69)=1.8$, NS, and no Time $\times$ Group interaction effects were found (craving: $F<1$, depression: $F(1,69)=2.8$, NS, tension: 
$F(1,69)=0$, NS), showing an absence of significant differential effects for both group.

The 2 (Group: bulimics vs normal controls) $\times 2$ (Time: exposure vs taste test) ANOVA's showed significant Time effects for HR, $F(1,62)=37, p<0.001$, FPA, $F(1,57)=$ 24.6, $p<0.001$, and SCL, $F(1,54)=19.4, p<0.001$. HR had increased during the exposure and increased further during the taste test; whereas FPA and SCL decreased to baseline values (see Table 2). Again, no Group effects and no Group $\times$ Time interactions were found (all $F^{\prime} \mathrm{s}<1$ ) meaning that there were no differences in physiological responding during food intake between the bulimics and the normal controls.

In sum, partial support was found for the first hypothesis. As expected, exposure to the sight and smell of food led to increased physiological responding. The confrontation with binge cues elicited physiological responses in all subjects: HR, SCL and FPA all augmented. The participants also reported a significantly increased urge to eat, worse mood and increased tension during the exposure. Although there were no differences in physiological responding between the bulimics and the control participants, the bulimics reported significantly less urge to eat and more depression during the baseline and exposure than the controls.

It is noteworthy that the increases in FPA and SCL were specific for the cue exposure manipulation: they decreased to baseline levels during the taste test, whereas HR kept increasing during the taste test.

Hypothesis 2: Participants diagnosed with bulimia nervosa eat more during a taste test following the cue exposure than the normal controls. Contrary to expectation, no difference in caloric intake during the taste test was found between the bulimics and the control participants (see Table 2). Both groups ate almost exactly the same amount of kilocalories during the $10 \mathrm{~min}$ eating time, $t(64)<1$. It is of interest here that three participants with bulimia nervosa refused on forehand to take part in the taste test but could be persuaded to do a $5 \mathrm{~min}$ taste test instead of $10 \mathrm{~min}$. In these $5 \mathrm{~min}$, three of them ate significantly more kilocalories $(M=774, \mathrm{SD}=469 \mathrm{kcal})$ than the other bulimics ate during the $10 \mathrm{~min}$ taste test, $(M=285, \mathrm{SD}=253 \mathrm{kcal}$, $t(46)=3.1, p<0.01)$. Obviously, these three bingers started to lose control over intake. Although the subgroup of three potential bingers is too small for meaningful statistical testing, a closer explorative look at their physiological and subjective responding during the food exposure showed clearly increased depression scores and substantially smaller increases in FPA in the three subjects than in the rest of the bulimics (see Fig. 1).

Hypothesis 3: The food intake of all subjects is positively related to their urge to eat and physiological cue reactivity. As expected, self-reported urge to eat during the cue exposure predicted caloric intake during the taste test $(r=0.36, p<0.01)$ : stronger urges to eat predicted larger caloric intake. Also, the FPA response during food exposure predicted the amount of calories eaten later, during the taste
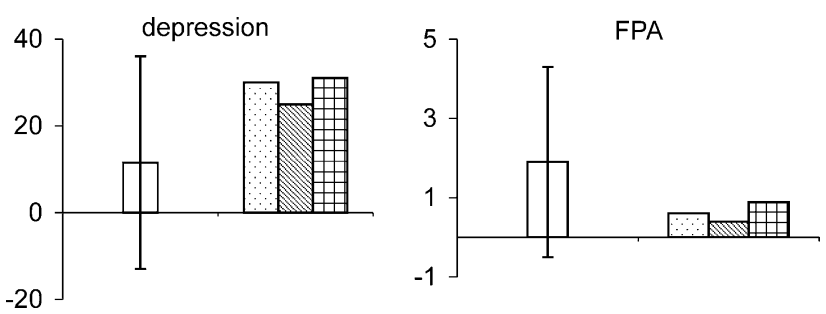

Fig. 1. Mean increases in depression and finger pulse amplitude (FPA) from baseline to exposure in the 44 binge eaters that completed a 10-min taste test (left-hand bar) vs the individual scores of the three binge eaters that lost control and completed a 5-min taste test (three right-hand bars).

test: participants with smaller increases in FPA during the exposure ate more during the subsequent taste test $(r=-0.26, p<0.05)$. A significant relation between the craving and FPA during the cue exposure was also found: smaller increases in FPA during the cue exposure were significantly related to stronger urges to eat $(r=-0.29$, $p<0.05)$.

Smaller increases in FPA during the taste test were also related to increased caloric intake during the taste test $(r=-0.37, p<0.01)$. HR increases during the taste test were also related to larger caloric intake $(r=0.27$, $p<0.05$ ), this might, however, be a simple consequence of making movements during eating. No other significant relations were found. In sum, the increased craving was significantly related to smaller increases in FPA, and both were related to increased caloric intake during the taste test.

\section{Discussion}

In the present study participants diagnosed with bulimia nervosa and control participants were exposed to their most favourite binge food (bulimics) or most favourite snacks (controls) and cue reactivity was measured. The exposure to the sight and smell of food led to increased physiological responding: HR, SCL and FPA augmented in all subjects. Also, self-reported urge to eat increased during the exposure and mood was more depressed. There were no differences in physiological responding between the bulimics and the control participants, but the bulimics reported significantly smaller urges to eat and significantly more depression during the baseline and exposure than the controls. Increased urge to eat during exposure was related to smaller increases in FPA, and both the self-reported urge to eat and smaller FPA increase during the exposure predicted increased caloric intake during the taste test. Both groups ate about the same amount of food during the taste test.

What do these data mean? An interesting finding in this study is that smaller FPA increases were related to increased urges and predicted increased food intake. To interpret this relation, first the increase in FPA during the exposure should be discussed. Although the FPA response 
was augmented during cue exposure, the direction was opposite to our expectations. A decrease in FPA (vasoconstriction) was predicted, caused by blood flowing to the stomach in anticipation of the food. During the taste test, when food must actually be digested, indeed vasoconstriction was found. But during the exposure, peripheral vasodilatation was found instead. It is possible that arousal and stress, caused by the exposure, is responsible for this finding. Arousal has an opposite effect on FPA (blood flows to skeletal muscles: Johnson \& Anderson, 1990) and the participants were more aroused during the exposure, as appears from the increased skin conductance and subjective tension during the exposure. Conceivably, two opposite processes determined the net effect on FPA. In this case, the overall increase in FPA reflected a dominant arousal effect. However, in subjects with a smaller increase, the preparation response was relative larger. Coming back to the relation between FPA, urges and food intake: in subjects with smaller increases in FPA, the preparatory effect is relatively more profound. This goes together with an increased urge for food and an increased food intake, which is in accordance with the conditioning theory of eating. In line with this, the exploratory data of the three bingers that seemed to have lost their control and overate showed obviously smaller FPA increases than the other binge eaters, a finding that supports the idea of smaller FPAs meaning intake preparation.

It was hypothesized that participants with bulimia nervosa would show stronger cue reactivity and larger food intake than the control participants but no support was found for this idea. The expected differences between the groups may be absent because conditioning plays a role in all eating behaviour: also the control participants show conditioned responses during exposure to their most favourite and most frequently eaten snacks. A most relevant question, then, is why not all conditioned responses lead to binge eating, and the answer might be that it is a matter of intensity. The food intake is the unconditioned stimulus (US) and it is well known that the intensity of the US determines the strength of conditioning and the size of the conditioned responses (Jansen, 1998). Normal eaters eat normal amounts and thus show normal size conditioned responses, whereas binge eaters eat large amounts (intense US) and thus might be expected to show large conditioned responses. The present experimental situation might have prevented most of the bulimics from developing an irresistible urge to overeat and large conditioned responses. The artificial situation, the presence of the experimenter, the electrodes and the turning table under their noses might have induced feelings of shame and embarrassment, thereby inhibiting the feelings of urge to eat, and promoting selfcontrol. The data of merely three subjects could be interpreted as overeating. Further research seriously should consider mobile testing; enabling measurements in more natural situations to overcome shame in an artificial and embarrassing situation might be more suitable to test the cue reactivity hypotheses.

During the exposure, the self-reported depression scores of clinical subjects were significantly higher than the depression scores of the control group. No group differences were found in the experienced tension or nervousness. These data support previous findings of Vögele and Florin (1997), who showed that negative affect is a main subjective experience that distinguishes eating disordered from noneating disordered subjects when exposed to food cues.

The present data also have some clinical value. If the urge to overeat is classically conditioned, i.e. when exposure to cues like the sight and smell of binge food elicit conditioned preparatory responses including an irresistible urge to overeat, the ultimate way to extinguish these responses is cue exposure with response prevention (CERP). By exposing the bulimics to cues that predict binge eating, while at the same time preventing the binger from actual intake, the bodily preparatory responses will eventually extinguish. There is some preliminary data that CERP is highly effective in binge eating reduction (Jansen, Broekmate, \& Heymans, 1992; Jansen, Elgersma, Nederkoorn, \& Smeets, 2002; Kennedy, Katz, Neitzert, Ralevsky, \& Mendlowitz, 1995; Toro et al., 2003) although the effect of addition of CERP to cognitive-behavioural therapy was limited (Bulik, Sullivan, Carter, McIntosh, \& Joyce, 1998). The present data point to FPA assessment during exposure as a valid measure of the effectiveness of CERP.

All in all, exposure to favourite binge or snack foods increases physiological and subjective responding in both bulimics and control participants. FPA, eating urges and food intake were related to each other: smaller increases in FPA correlated with larger urges to eat and both predicted larger food intake. Smaller increases in FPA might reflect classically conditioned bodily reactions that prepare for eating. Further studies into the role of FPA in the experienced irresistible urge to overeat are needed, and when FPA indeed is found to reflect the trigger to overeat, exposure with response prevention is the ultimate way to extinguish the classically conditioned FPA and urge response.

\section{Acknowledgements}

The authors acknowledge with gratitude the support of Annie Raven, the Academic Unit for Cognitive Behavior Therapy of the Community Mental Health Center of Maastricht, Anja Meijboom, Theo van Aarts, Huub Hamers, Peter de Jong and Han Keizers.

\section{References}

American Psychiatric Association (1994). Diagnostic and statistical manual of mental disorders (4th ed.). Washington, DC: American Psychiatric Association. 
Bulik, C. M., Lawson, R. H., \& Carter, F. A. (1996). Salivary reactivity in restrained and unrestrained eaters and women with bulimia nervosa. Appetite, 27, 15-24.

Bulik, C. M., Sullivan, P. F., Carter, F. A., McIntosh, V. V., \& Joyce, P. R. (1998). The role of exposure with response prevention in the cognitivebehavioural therapy for bulimia nervosa. Psychological Medicine, 28, 611-623.

Carter, F. A., Bulik, C. M., McIntosh, V. V., \& Joyce, P. R. (2001). Changes in cue reactivity following treatment for bulimia nervosa. International Journal of Eating Disorders, 29, 336-344.

Jansen, A. (1998). A learning model of binge eating: cue reactivity and cue exposure. Behaviour Research and Therapy, 36, 257-272.

Jansen, A., Broekmate, J., \& Heymans, M. (1992). Cue exposure vs selfcontrol in the treatment of binge eating: a pilot study. Behaviour Research and Therapy, 30, 235-241.

Jansen, A., Elgersma, H., Nederkoorn, C., Smeets, T (2002). What makes treatment of bulimia nervosa successful? Paper presented at the European Association for Behavioural and Cognitive Therapies (EABCT), Maastricht.

Johnson, A. K., \& Anderson, E. A. (1990). Stress and arousal. In J. T. Cacioppo, \& L. G. Tassinary (Eds.), (pp. 216-252). Principles of psychophysiology. Physical, social and inferential elements, New York: Cambridge University Press.

Karhunen, L. J., Lappalainen, R. I., Tammela, L., Turpeinen, A. K., \& Uusitupa, M. I. J. (1997). Subjective and physiological cephalic phase responses to food in obese binge eating women. International Journal of Eating Disorders, 21, 321-328.

Karhunen, L. J., Lappalainen, R. I., Vanninen, E. J., Kuikka, J. T., \& Uusitupa, M. I. J. (1997). Regional cerebral blood flow during food exposure in obese and normal-weight women. Brain, 120, 1675-1684.

Kennedy, S. H., Katz, R., Neitzert, C. S., Ralevsky, E., \& Mendlowitz, S. (1995). Exposure with response prevention treatment of anorexia nervosa-bulimic subtype and bulimia nervosa. Behaviour Research and Therapy, 33, 685-689.

Mattes, R. D. (1997). Physiologic responses to sensory stimulation by food: nutritional implications. Journal of the American Diet Association, 97, 406-410. see also page 413.

Nederkoorn, C., Smulders, F. T. Y., \& Jansen, A. (2000). Cephalic phase responses, craving and food intake in normal subjects. Appetite, 35, 45-55.

Spitzer, R. L., \& Williams, J. B. W. (1986). Structured clinical interview for DSM-III-R (SCID). New York: New York State Psychiatric Institute, Biometric Research.

Staiger, P., Dawe, S., \& McCarthy, R. (2000). Responsivity to food cues in bulimic women and controls. Appetite, 35, 27-33.

Teff, K. L., \& Engelman, K. (1996). Palatability and dietary restraint: effect on cephalic phase insulin release in women. Physiology and Behavior, $60,567-573$

Tepper, B. J. (1992). Dietary restraint and responsiveness to sensory-based food cues as measured by cephalic phase salivation and sensory specific satiety. Physiology and Behavior, 52, 305-311.

Toro, J., Cervera, M., Feliu, M. H., Garriga, N., Jou, M., Martinez, E., \& Toro, E. (2003). Cue exposure in the treatment of resistant bulimia nervosa. International Journal of Eating Disorders, 34, $227-234$.

Tuomisto, T., Hetherington, M. M., Morris, M., Tuomisto, M. T., Turjanmaa, V., \& Lappalainen, R. (1999). Psychological and physiological characteristics of sweet food 'addiction'. International Journal of Eating Disorders, 25, 169-175.

Vögele, C., \& Florin, I. (1997). Psychophysiological responses to food exposure: an experimental study in binge eaters. International Journal of Eating Disorders, 21, 147-157. 